\title{
Mitochondria-dependent signalling pathway are involved in the early process of radiation-induced bystander effects
}

\author{
S Chen', Y Zhao', W Han', G Zhao', L Zhu', J Wang', L Bao', E Jiang', A Xu', TK Hei², Z Yu' and L Wu*,I \\ 'Key Laboratory of Ion Beam Bioengineering, Institute of Plasma Physics, Chinese Academy of Sciences, Hefei 23003I, People's Republic of China; \\ ${ }^{2}$ Center for Radiological Research, College of Physicians and Surgeons, Columbia University, New York, NY 10032, USA
}

Bystander effects induced by cytoplasmic irradiation have been reported recently. However, the mechanism(s) underlying, such as the functional role of mitochondria, is not clear. In the present study, we used either mtDNA-depleted $\left(\rho^{0}\right) A_{L}$ or normal $\left(\rho^{+}\right) A_{L}$ cells as irradiated donor cells and normal human skin fibroblasts as receptor cells in a series of medium transfer experiments to investigate the mitochondria-related signal process. Our results indicated that mtDNA-depleted cells or normal $A_{L}$ cells treated with mitochondrial respiratory chain function inhibitors had an attenuated $\gamma-\mathrm{H} 2 \mathrm{AX}$ induction, which indicates that mitochondria play a functional role in bystander effects. Moreover, it was found that treatment of normal $A_{L}$ donor cells with specific inhibitors of NOS, or inhibitor of mitochondrial calcium uptake (ruthenium red) significantly decreased $\gamma-\mathrm{H} 2 \mathrm{AX}$ induction and that radiation could stimulate cellular $\mathrm{NO}$ and $\mathrm{O}_{2}^{\bullet-}$ production in irradiated $\rho^{+} \mathrm{A}_{L}$ cells, but not in $\rho^{0} \mathrm{~A}_{L}$ cells. These observations, together with the findings that ruthenium red treatment significantly reduced the $\mathrm{NO}$ and $\mathrm{O}_{2}^{\bullet-}$ levels in irradiated $\rho^{+} \mathrm{A}_{\mathrm{L}}$ cells, suggest that radiationinduced NO derived from mitochondria might be an intracellular bystander factor and calcium-dependent mitochondrial NOS might play an essential role in the process.

British Journal of Cancer (2008) 98, I839-1844. doi:I0.1038/sj.bjc.6604358 www.bjcancer.com

Published online 13 May 2008

(c) 2008 Cancer Research UK

Keywords: radiation-induced bystander effects; signalling pathway; mitochondrion; nitric oxide synthase

Although radiation-induced bystander effects (RIBEs) have generated a lot of interest in the field of radiation biology, the mechanism(s) underlying the bystander phenomenon are not quite clear. Emerging evidence indicates that soluble transmissible factor(s) and gap junction-mediated cell-cell communications are critical in mediating the bystander effects (Mothersill and Seymour, 1998; Azzam et al, 2001). Moreover, there is evidence that cytoplasmic irradiation may also be capable of inducing the bystander signalling molecules. Earlier report by $\mathrm{Wu}$ et al (1999) indicated that irradiating only cytoplasm resulted in CD59 locus mutations in the human-hamster hybrid $\left(\mathrm{A}_{\mathrm{L}}\right)$ cells. Recently, Shao et al (2004) reported that when a single cell within the glioma population was traversed through its cytoplasm with one helium ion, bystander response was induced in the neighbouring, nonirradiated glioma or fibroblasts. In our previous studies, we demonstrated that the induction of excessive $\gamma$-H2AX could be detected in bystander cells within minutes after irradiation $\mathrm{Hu}$ et al, 2005; Han et al, 2007b), and NO produced by constitutive nitric oxide synthase (cNOS) was identified as the possible intercellular signalling molecule to initiate and activate bystander signalling pathway in the early process (Han et al, 2007a). However, the exact locations where the signalling molecule(s), such as reactive oxygen/nitrogen species (RNS/ROS), are generated in the cytoplasm and what is the role of mitochondria in the early processes of RIBE remain unknown.

*Correspondence: Dr L Wu; E-mail: ljw@ipp.ac.cn

Revised 21 January 2008; accepted 12 March 2008; published online 13 May 2008
Mitochondria occupy a unique position among cellular organelles and play an important role in the generation of free radicals and in the regulation of apoptosis (Balaban et al, 2005). Ionising radiation has been found to induce mitochondrial damage by increase of ROS production, depolarisation of mitochondrial membrane potential, and release of cytochrome $c$ in directly irradiated cells (Leach et al, 2001). There is also evidence that irradiated cell conditioned media (ICCM) can cause changes of mitochondrial distribution, loss of mitochondrial membrane potential, increases in ROSs, and increase in apoptosis among the medium receptor cells, which can be blocked by treatments with antioxidants (Lyng et al, 2000; Maguire et al, 2005). Furthermore, Limoli et al (2003) have reported that a state of chronic oxidative stress derived in part from dysfunctional mitochondria may be linked to many of the abnormal phenotypes associated with genomic instability in the progeny of irradiated cells.

In the present studies, we investigated the role of mitochondria in the formation and transduction of signals during the early stage of the bystander process. To address these goals, a medium transfer approach was adopted, and normal $A_{L}$ cells $\left(\rho^{+}\right)$and mitochondrial DNA (mtDNA)-depleted $A_{L}$ cells $\left(\rho^{0}\right)$ were used as medium donor cells, whereas AG1522 cells were used as the medium receptor cells. With the detection of $\gamma-\mathrm{H} 2 \mathrm{AX}$ foci induction in receptor cells and the determination of the origin of $\mathrm{NO}$ and $\mathrm{O}_{2}^{\bullet-}$ in irradiated cells, our results suggested that mitochondria-derived $\mathrm{NO}$ and $\mathrm{O}_{2}^{\bullet-}$ played an important role in the initiation and activation of the early process $(\leqslant 30 \mathrm{~min})$ of RIBE. 


\section{MATERIALS AND METHODS}

\section{Cell culture}

Two hamster cell lines: normal $\mathrm{A}_{\mathrm{L}}$ cells $\left(\rho^{+}\right)$and mtDNA-depleted $\mathrm{A}_{\mathrm{L}}$ cells $\left(\rho^{0}\right)$ together with normal human fibroblasts in passage 11-14 (AG1522) were used in the present studies. $A_{L}$ cells $\left(\rho^{0}\right)$ were generated in the laboratory of one of the co-authors (TK Hei) by treating normal $\mathrm{A}_{\mathrm{L}}$ cells with the chemotherapeutic drug ditercalinium over a period of 3-4 months to deplete the mtDNA by $>95 \%$ (Liu et al, 2005). All cells were cultured and maintained at $37^{\circ} \mathrm{C}$ in a humidified $95 \%$ air $/ 5 \% \mathrm{CO}_{2}$ incubator. For media transfer study, $\rho^{+} \mathrm{A}_{\mathrm{L}}$ cells and $\rho^{0} \mathrm{~A}_{\mathrm{L}}$ cells were used as medium donor cells after irradiation, and AG1522 cells were used as medium receptor cells.

\section{$\alpha$-Particle irradiation and medium transfer experiments}

The average energy and LET of $\alpha$-particles derived from the ${ }^{241} \mathrm{Am}$ irradiation source of the radiation facility, measured at the cell

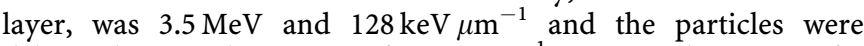
delivered at a dose rate of $1.0 \mathrm{cGys}^{-1}$. For medium transfer experiment, $\rho^{+} \mathrm{A}_{\mathrm{L}}$ cells and $\rho^{0} \mathrm{~A}_{\mathrm{L}}$ cells under confluent conditions in a $35-\mathrm{mm}$ stainless steel dish with a $3.5-\mu \mathrm{m}$-thick replaceable mylar bottom were placed on the rotating sample bracket and irradiated with a 1 -cGy dose of $\alpha$-particles. After irradiation, the cultures were put back into the incubator for $10 \mathrm{~min}$. Then, the medium from the irradiated population was collected, filtered through a $0.8-\mu \mathrm{m}$ syringe filter, and transferred immediately into a rectangular dish $\left(10 \times 6 \mathrm{~mm}^{2}\right)$ full of nonirradiated, confluent AG1522 cells ( $>92 \%$ cells in G1 phase). Thereafter, these receptor cells were incubated for $30 \mathrm{~min}$ with ICCM and then fixed with $2 \%$ paraformaldehyde solution for immunostaining. Medium from sham-irradiated dish was transferred to the receptor cells as controls.

\section{Immunostaining for $\gamma$ - $\mathrm{H} 2 \mathrm{AX}$}

For the immunostaining, the fixed cells were permeabilised in TNBS solution (PBS supplemented with $0.1 \%$ Triton X-100 and $1 \%$ FBS), followed by exposing cells to anti- $\gamma$-H2AX primary antibody (Upstate Biotechnology, Lake Placid, New York, USA) for $1 \mathrm{~h}$. Then, the cells were incubated with fluorescein isothiocyanateconjugated goat anti-mouse secondary antibody (Haoyang Biological Manufacture Company, Tianjin, China) for another $1 \mathrm{~h}$. After washing with TNBS for $3 \times 5 \mathrm{~min}$, cells were counterstained with $5 \mathrm{mg} \mathrm{ml}^{-1}$ Hoechst 33342 (Molecular Probes, Eugene, Oregon, USA).

Immunofluorescent images were captured by confocal laser scanning microscope (TCS SP2; Leica, Wetzlar, Germany). For quantitative analysis, the cells with at least one $\gamma$-H2AX focus were regarded as the positive cells and the fraction of positive cells was calculated (cells with $\gamma$-H2AX foci/total cells) (Limoli et al, 2002; $\mathrm{Hu}$ et al, 2005). At least 700 cells in each sample were counted, and the fraction of positive cells of irradiated groups was normalised to their nonirradiated controls. Statistical analyses were performed on the means of the data obtained from at least three independent experiments.

\section{$\gamma-\mathrm{H} 2 \mathrm{AX}$ induction in receptor cells after pretreatment with inhibitors of mitochondrial respiratory chain function}

Before irradiation, the medium in the $\rho^{+} \mathrm{A}_{\mathrm{L}}$ donor cells was replaced with fresh medium containing either $1 \mu \mathrm{M}$ rotenone (Sigma, Steinheim, Germany) for $30 \mathrm{~min}, 5 \mu \mathrm{g} \mathrm{ml}^{-1}$ antimycin A (Sigma, Steinheim, Germany) for $2 \mathrm{~h}$, or $10 \mu \mathrm{m}$ oligomycin (Sigma, Steinheim, Germany) for $1 \mathrm{~h}$ to inhibit respiratory chain complexes I, III, or V, respectively. After washing twice with D-Hanks buffer, and being replenished with fresh media, cells were irradiated with $1 \mathrm{cGy} \alpha$-particles, and the media were, subsequently, transferred to receptor cells $10 \mathrm{~min}$ later as described previously.

\section{$\gamma-\mathrm{H} 2 \mathrm{AX}$ induction in receptor cells after pretreatment with inhibitors of nitric oxide synthase}

The medium in the $\rho^{+} \mathrm{A}_{\mathrm{L}}$ donor cells was replaced with fresh media containing $1 \mathrm{mM} \quad \mathrm{N}^{\mathrm{G}}$-methyl-L-arginine (L-NMMA; Molecular Probes, Eugene, Oregon, USA) for $1 \mathrm{~h}, 1 \mathrm{mM} \mathrm{N} \mathrm{N}^{\mathrm{G}}$ methyl-D-arginine (D-NMMA; Molecular Probes) for $1 \mathrm{~h}$, or $1 \mu \mathrm{M}$ $\mathrm{N}^{\omega}$-nitro-L-arginine (L-NNA; Sigma, Steinheim, Germany) for $30 \mathrm{~min}$, respectively. $\mathrm{N}^{\mathrm{G}}$-methyl-L-arginine, is a specific inhibitor of NOS, D-NMMA is the nonreactive D-enantiomer of L-NMMA, and L-NNA is an irreversible inhibitor of cNOS. All inhibitortreated cells were washed with D-Hanks buffer before irradiation. After irradiation, the donor cells culture was incubated for $10 \mathrm{~min}$, and, then, the medium was immediately collected and transferred to the receptor cells as described above.

\section{$\gamma-\mathrm{H} 2 \mathrm{AX}$ induction in receptor cells after pretreatment with inhibitors of calmodulin and mitochondrial calcium uptake}

Confluent $\rho^{+} \mathrm{A}_{\mathrm{L}}$ donor cells were preincubated with $10 \mu \mathrm{M}$ calmidazolium chloride (Calbiochem, Darmstadt, Germany) for $10 \mathrm{~min}$ or $10 \mu \mathrm{M}$ ruthenium red (RR; Fluka, Steinheim, Germany) for $2 \mathrm{~min}$ (Dedkova et al, 2004). Calmidazolium chloride is an inhibitor of calmodulin binding with NOS, and RR is an inhibitor of mitochondrial calcium uptake. After irradiation, the media containing inhibitors were removed at once, and cells were incubated in fresh media for $10 \mathrm{~min}$. Finally, the media were transferred into the receptor cells as described above.

\section{$\mathrm{NO}$ and $\mathrm{O}_{2}^{\bullet-}$ measurement in donor cells}

The 4-amino-5-methylamino-2', $7^{\prime}$-difluorofluorescein diacetate (DAF-FM diacetate; Molecular Probes, Eugene, Oregon, USA) and dihydroethidine (Molecular Probes, Eugene, Oregon, USA) were employed to quantify the level of $\mathrm{NO}$ and $\mathrm{O}_{2}^{\bullet-}$, respectively, as described (Narayanan et al, 1997; Wan et al, 2005; Han et al, 2007a). At confluency, cultures $\left(\rho^{+}\right.$and $\left.\rho^{0}\right)$ inoculated on the mylar film in $14-\mathrm{mm}$ stainless steel dishes were stained with $5 \mu \mathrm{M}$ DAF-FM diacetate in Tyrode's solution or $10 \mu \mathrm{m}$ dihydroethidine in D-Hanks for $30 \mathrm{~min}$ in incubator. The cultures were then irradiated with $1 \mathrm{cGy} \alpha$-particles followed by a 10 -min incubation at $37^{\circ} \mathrm{C}$. The fluorescence intensity was measured with a fluorescent reader (excitation/emission: 495/515 nm for NO, 488/ $610 \mathrm{~nm}$ for $\mathrm{O}_{2}^{\bullet-}$ ), and the fluorescence intensity in $1 \mathrm{cGy}$-irradiated cultures was normalised to the sham-irradiated cultures. Statistical analysis was performed on the means of the data pooled from at least three independent experiments.

\section{Effect of mitochondrial calcium uptake on the $\mathrm{O}_{2}^{\circ-}$ and $\mathrm{NO}$ products}

To investigate the effect of mitochondrial calcium uptake on the $\mathrm{NO}$ and $\mathrm{O}_{2}^{\bullet-}$ products in irradiated donor cells, cells preloaded with either DAF-FM diacetate or dihydroethidine were treated with $\mathrm{RR}$ for $2 \mathrm{~min}$. The cultures were then irradiated, washed with buffer at once, and fluorescence intensities detected by fluorescence reader as described above.

\section{Statistical analysis}

Data were presented as mean and standard derivations. Comparisons of the $\gamma-\mathrm{H} 2 \mathrm{AX}$ induction and fluorescent intensity between treated groups and controls were made by Student's $t$-test. A 
$P$-value of 0.05 or less between groups was considered to be significant.

\section{RESULTS}

mtDNA-depletion and inhibition of respiratory chain function attenuate the bystander $\gamma-\mathrm{H} 2 \mathrm{AX}$ induction

The background $\gamma-\mathrm{H} 2 \mathrm{AX}$ induction in AG1522 cells by ICCM from either $\rho^{+}$or $\rho^{0} \mathrm{~A}_{\mathrm{L}}$ cells $\left(\rho^{+} / \rho^{0}\right.$ ICCM $)$ without irradiation was quite similar $\left(17.1 \pm 1.6 \%\right.$ for $\rho^{+}$cells and $16.3 \pm 1.3 \%$ for $\rho^{0}$ cells $)$. After irradiation, as shown in Figure 1A, the $\gamma$-H2AX induction of $\rho^{+} / \rho^{0}$ ICCM were significantly higher than their nonirradiated controls (increased by $31 \%, P<0.01$ for $\rho^{+}$cells; increased by $13 \%, P<0.05$ for $\rho^{0}$ cells). However, the $\gamma-\mathrm{H} 2 \mathrm{AX}$ induction of $\rho^{+}$ ICCM was significantly higher than that of $\rho^{0} \operatorname{ICCM}(P<0.05)$. These results clearly show that $\rho^{0}$ cells have a lower $\gamma$-H2AX induction ability than wild-type cells and suggest that mitochondria may play a functional role in the early processes of RIBE.

To further investigate if the dysfunction of mitochondrial respiratory chain was related to the attenuated $\gamma-\mathrm{H} 2 \mathrm{AX}$ induction of $\rho^{0}$ ICCM, $\rho^{+} \mathrm{A}_{\mathrm{L}}$ cells were treated with specific inhibitors of respiratory chain complex before irradiation. As shown in Figure 1B, Rotenone, antimycin $\mathrm{A}$, and oligomycin suppressed the $\gamma-\mathrm{H} 2 \mathrm{AX}$ induction in the receptor cells $(P<0.05)$. These results indicate that respiratory chain complexes I, III, and V contribute to the generation of early signalling molecules in radiationinduced bystander processes.

Inhibitors of NOS decrease the bystander $\gamma-\mathrm{H} 2 \mathrm{AX}$ induction and radiation stimulates cellular NO production in irradiated $\rho^{+} \mathrm{A}_{\mathrm{L}}$ cells, but not in $\rho^{0} \mathrm{~A}_{\mathrm{L}}$ cells

To confirm whether the activity of NOS in irradiated $\rho^{+} \mathrm{A}_{\mathrm{L}}$ donor cells is critical in bystander signalling, the donor cultures were treated with L-NMMA, D-NMMA, or L-NNA before irradiation. As shown in Figure 2A, L-NMMA significantly quenched the $\gamma$-H2AX induction of $\rho^{+}$ICCM in receptor cells $(P<0.01)$, whereas the nonreactive D-enantiomer, D-NMMA, employed as negative control, showed no significant effect on $\gamma-\mathrm{H} 2 \mathrm{AX}$ induction $(P>0.05)$. Similarly, L-NNA significantly inhibited the $\gamma$-H2AX induction of $\rho^{+}$ICCM in receptor cells $(P<0.01)$.

By further measuring the level of NO in $\rho^{+}$or $\rho^{0} \mathrm{~A}_{\mathrm{L}}$ cells after irradiation with the fluorescent probes, DAF-DA diacetate, Figure $2 \mathrm{~B}$ showed that the fluorescence intensities of DAF-triazole, the fluorescent byproduct of DAF-FM, were significantly increased in $1 \mathrm{cGy}$-irradiated $\rho^{+} \mathrm{A}_{\mathrm{L}}$ cells comparing with the shamirradiated control $(P<0.05)$ and the increased fluorescence intensities of DAF-triazole were caused by NO (Supplementary Figure 1). In contrast, $\rho^{0} \mathrm{~A}_{\mathrm{L}}$ cells showed no significant induction relative to controls $(P>0.05$; Figure $2 \mathrm{~B})$. These results further confirm that activity of cNOS is causally linked to the early processes of RIBE and that radiation-induced NO products are derived from mitochondria.

\section{Inhibitors of calmodulin/mitochondrial calcium uptake decrease the bystander $\gamma-\mathrm{H} 2 \mathrm{AX}$ induction and radiation-induced NO production}

The activation of mitochondrial nitric oxide synthase (mtNOS) is known to be $\mathrm{Ca}^{2+}$ dependent. Consequently, RR and calmidazolium were used to further corroborate the role of calcium signalling in bystander effects. As shown in Figure 3A, pretreatment of cells with RR or calmidazolium significantly reduced the $\gamma$-H2AX induction of $\rho^{+} \operatorname{ICCM}(P<0.01$; Figure $3 \mathrm{~A})$. Moreover, treatment with RR also significantly decreased NO products in $\rho^{+}$ donor cells $(P<0.05$; Figure $3 \mathrm{~B})$. These data suggest that radiationinduced calcium flux is necessary for the induction of the bystander $\gamma$-H2AX, probably through the activation of mtNOS on the inner membranes of mitochondria.

\section{Radiation stimulates cellular $\mathrm{O}_{2}^{\circ-}$ production in irradiated} $\rho^{+} \mathrm{A}_{\mathrm{L}}$ cells, but not in $\rho^{0} \mathrm{~A}_{\mathrm{L}}$ cells

To monitor the levels of $\mathrm{O}_{2}^{\bullet-}$ in $\rho^{+}$or $\rho^{0} \mathrm{~A}_{\mathrm{L}}$ cells after irradiation, the fluorescent probe, dihydroethidine, was employed. Figure $4 \mathrm{~A}$ showed that the relative fluorescence intensity of ethidium bromide (EB), the fluorescent product of dihydroethidine when reacted with $\mathrm{O}_{2}^{\bullet-}$, was significantly increased in $1 \mathrm{cGy}$-irradiated $\rho^{+} \mathrm{A}_{\mathrm{L}}$ cells comparing with the sham-irradiated control $(P<0.05)$ and the increased EB fluorescence intensities were derived from superoxide anion (Supplementary Figure 1). In contrast, there was no significant increase EB $1 \mathrm{cGy}$-irradiated $\rho^{0} \mathrm{~A}_{\mathrm{L}}$ cells $(P>0.05)$. Moreover, treatment with $\mathrm{RR}$ also significantly decreased $\mathrm{O}_{2}^{\bullet}$ products in $\rho^{+}$donor cells $(P<0.05$; Figure $4 \mathrm{~B})$. This result provides further evidence that radiation-induced ROSs are derived from mitochondria and mitochondrial calcium uptake upregulate ROS products.

\section{DISCUSSION}

Mitochondria, which are ubiquitous in the cytoplasm of a cell, are important targets of radiation-induced cellular responses including apoptosis and oxyradical production (Belka et al, 2000; Leach et al, 2001). The prominence of mitochondrial function in radiation response has become more significant after bystander
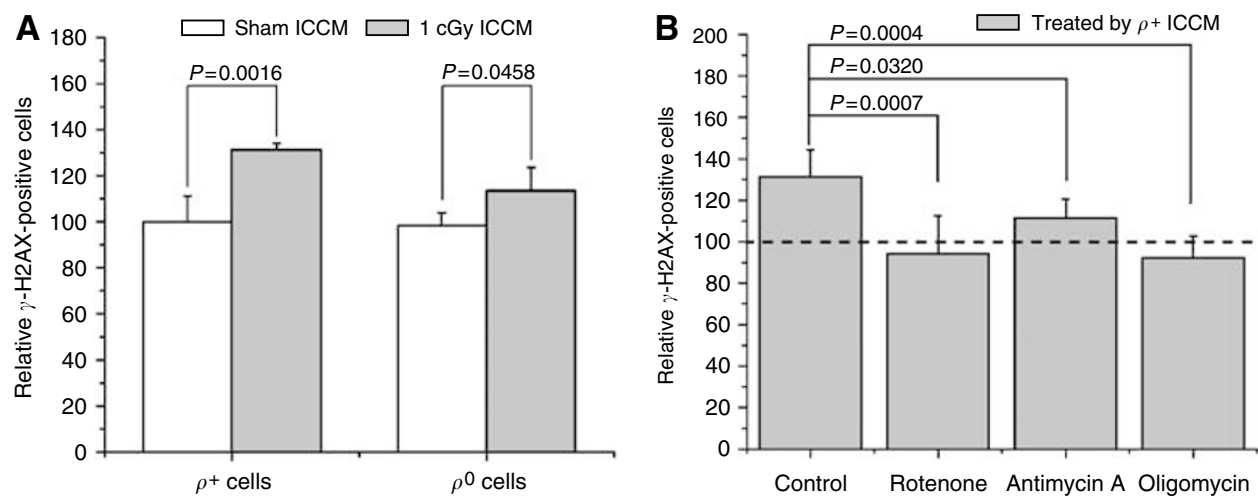

Figure I Effects of depleted mtDNA and inhibition of respiratory chain function on the bystander $\gamma-\mathrm{H} 2 \mathrm{AX}$ induced by ICCM. The $\gamma$-H2AX induction ability of $\rho^{+}$ICCM was significantly higher than that of $\rho^{0}$ ICCM $(1.31 \pm 0.03 \mathrm{vs} I .13 \pm 0.10, P<0.01, \mathbf{A})$ and the response was suppressed significantly by inhibitors of respiratory chain $(P<0.05, \mathbf{B})$. Data are pooled from at least three independent experiments and the results represent mean \pm s.d. 

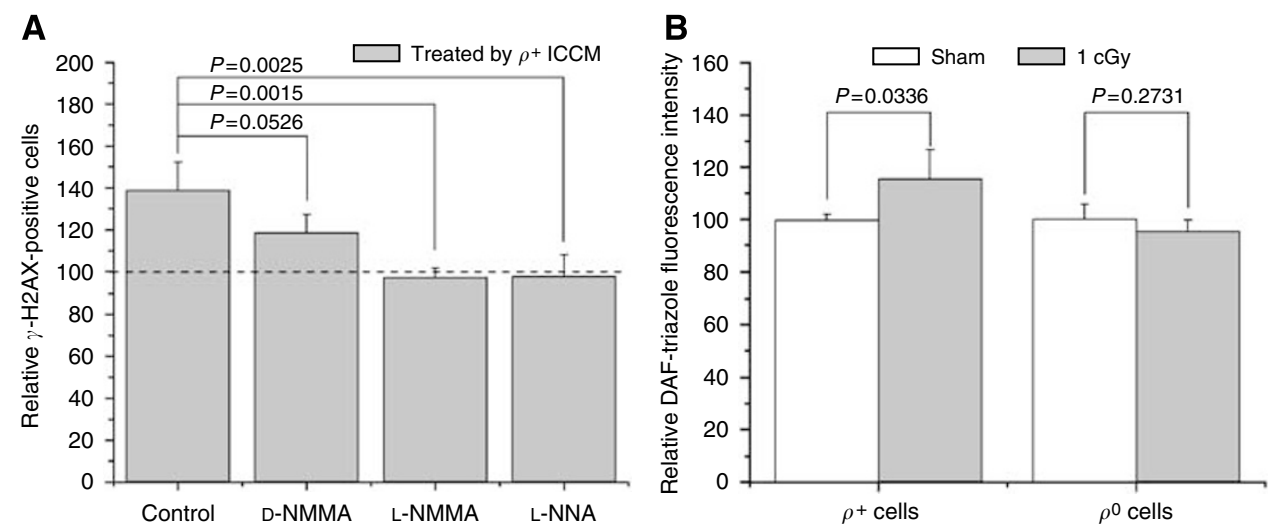

Figure 2 Effect of the NO products on the bystander $\gamma$-H2AX induction by $\rho^{+}$ICCM. NOS inhibitors, L-NMMA, or L-NNA significantly decreased $\rho^{+}$ ICCM-induced bystandery-H2AX $(\mathbf{A})$, and fluorescence intensities of DAF-triazole was significantly increased in I cGy-irradiated $\rho^{+} \mathrm{A}_{\llcorner}$cells, but not in I cGy-irradiated $\rho^{0} A_{L}$ cells $(\mathbf{B})$. Data are pooled from at least three independent experiments and the results represent mean \pm s.d.

A

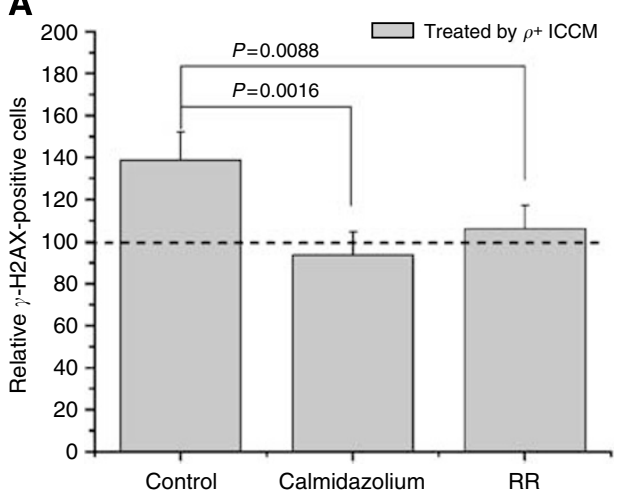

B

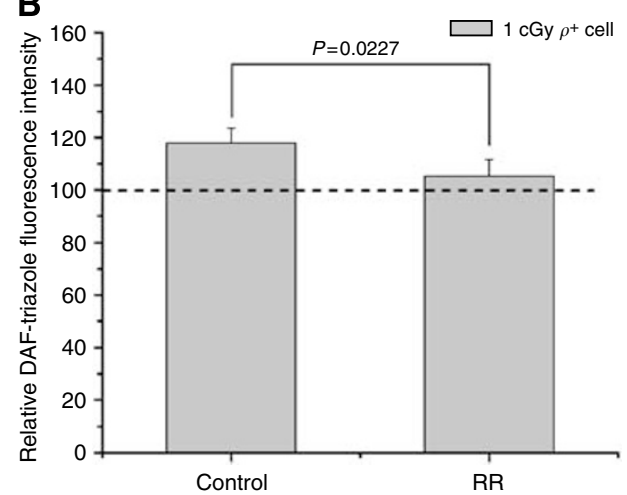

Figure 3 Effect of the calmodulin/ $\mathrm{Ca}^{2+}$ influx inhibition on the NO products and bystander $\gamma$-H2AX induction by $\rho^{+}$ICCM. RR or calmidazolium significantly reduced the $\gamma$-H2AX induction of $\rho^{+}$ICCM $(P<0.0$ I, A $)$. RR also significantly decreased NO products in irradiated $\rho^{+}$donor cells $(P<0.05$, B). Data are pooled from at least three independent experiments and the results represent mean \pm s.d.
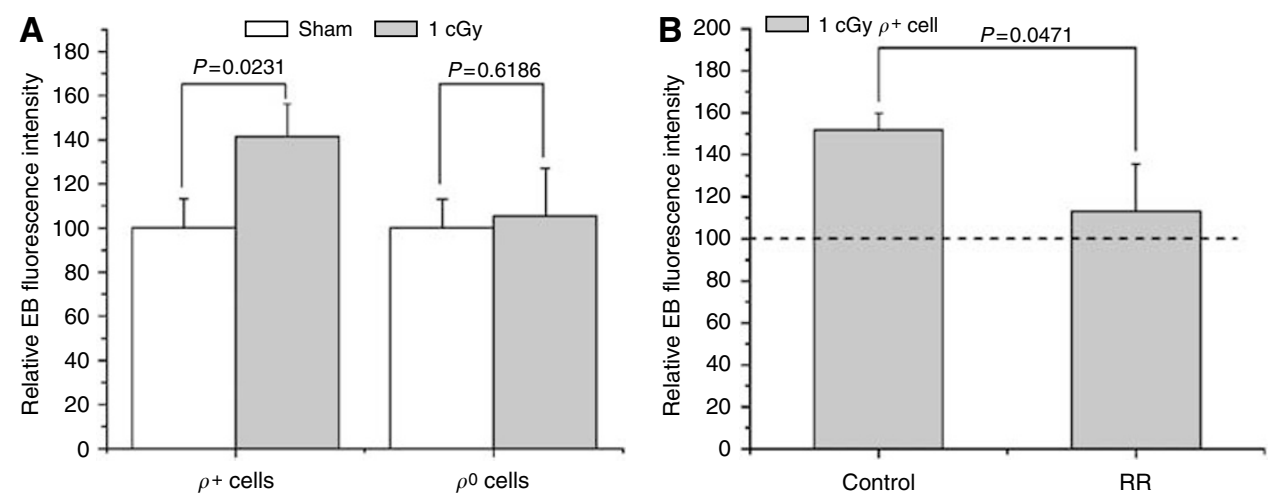

Figure 4 Effects of irradiation on the EB fluorescence intensity. The relative EB fluorescence intensities in I cGy-irradiated $\rho^{+} \mathrm{A}_{L}$ cells were significantly increase in 10 min after irradiation $(P<0.05)$, whereas there was no significant increase in I cGy-irradiated $\rho^{0} A_{L}$ cells $(P>0.05, n=3, \mathbf{A})$. Pretreatment with $10 \mu \mathrm{m}$ RR reduced the relative EB to background levels in I cGy-irradiated $\rho^{+} \mathrm{A}_{\mathrm{L}}$ cells in 10 min after irradiation $(P<0.05, \mathbf{B})$. Data are pooled from at least three independent experiments, and the results are represented as mean \pm s.d.

effects were observed in experiments of cytoplasmic irradiation (Wu et al, 1999; Shao et al, 2004). These studies suggest that direct nuclear damage is not required for switching on cell-signalling mechanisms (Morgan and Sowa, 2006) and damage to cytoplasm can also generate damage signals. Thus, the critical question is how the damage or damage signals are generated and whether it is related to mitochondrial damage as a result of cytoplasmic irradiation. In the present study, using mtDNA-depleted and normal cells and the induction of $\gamma-\mathrm{H} 2 \mathrm{AX}$ foci as a biological end point (Burdak-Rothkamm et al, 2007) in nonirradiated AG1522 cells, we investigated the role of mitochondria in the early process of RIBE. The results indicate that mtDNA-depleted cells or normal 
$A_{L}$ cells treated with mitochondrial respiratory chain function inhibitors have an attenuated $\gamma-\mathrm{H} 2 \mathrm{AX}$ induction (Figure 1A and $B)$, which clearly suggest that mitochondria play a crucial role in the early processes of RIBE. Moreover, our results using $A_{L}$ cells as donor cells and human fibroblasts as receptor cells, clearly illustrate that in the early process, RIBE is not cell-type dependent and the signal can be transferred across species. Furthermore, the relatively low $\gamma-\mathrm{H} 2 \mathrm{AX}$ induction by irradiated medium from $\rho^{0}$ cells suggests that other signal production pathways are likely to be involved in the early processes of RIBE.

The role of soluble transmissible factor(s), such as ROSs, RNSs, and cytokines generated by irradiated cells that in turn induce toxic effects in nonirradiated cells, has been demonstrated by many medium transfer experiments (Mothersill and Seymour, 1998; Lyng et al, 2000). Leach et al (2002) observed that activation of cNOS activity was an early signal event after irradiation. Recent studies have demonstrated the important role of constitutive NO in mediating the early bystander responses induced by low-dose irradiation (Han et al, 2007a). In the present study using inhibitors of NOS, including specific inhibitor of cNOS, we found that, consistent with our previous observations with AG1522 cells, the $\gamma$-H2AX induction of $\rho^{+}$ICCM was significantly decreased (Figure 2A) and ionising radiation stimulated cellular NO production in irradiated $\rho^{+} \mathrm{A}_{\mathrm{L}}$ cells, but not in $\rho^{0} \mathrm{~A}_{\mathrm{L}}$ cells (Figure $2 \mathrm{~B}$ ). These results suggest that activity of NOS in $\rho^{+} \mathrm{A}_{\mathrm{L}}$ cells, especially cNOS, is involved in the early processes of RIBEs and mitochondria might be a main source in the generation of NO.

Using a variety of approaches including immunohistochemistry, western blotting, fluorescent staining, $\mathrm{NOS}^{-1-}$ mice, and microsensors, mtNOS has been shown to be distributed in diverse organs of many species (Bates et al, 1995; Kanai et al, 2001, 2004; Kato and Giulivi, 2006; Ghafourifar and Sen, 2007). Changes in mtNOS expression and activity in many pathophysiological situations may imply its significant involvement in various NOrelated biological phenomena. In contrast, there have been reports that raised doubts on the existence of mtNOS based on methodological issues, and speculated that eNOS, which is attached to the outer mitochondrial membrane, mediates the release of NO (Lacza et al, 2006). However, this hypothesis is very difficult to explain, as NO production can be significantly decreased by preventing mitochondrial $\mathrm{Ca}^{2+}$ uptake. Recently, Ghafourifar and his colleagues have reported that hypoxia/ reoxygenation and tamoxifen can elevate $\left[\mathrm{Ca}^{2+}\right]_{\mathrm{m}}$ by increasing mitochondrial calcium uptake and the release of $\left[\mathrm{Ca}^{2+}\right]_{\mathrm{m}}$ from the granules in mitochondria, and stimulate mtNOS to generate NO (Nazarewicz et al, 2007; Zenebe et al, 2007). By inhibiting mitochondrial calcium uptake with $\mathrm{RR}$, we found that the relative fluorescence intensity of NO significantly decreased in postirradiated $\rho^{+} \mathrm{A}_{\mathrm{L}}$ cells (Figure $3 \mathrm{~B}$ ). Moreover, treatment with RR resulted in a significant decreased in $\gamma-\mathrm{H} 2 \mathrm{AX}$ induction of $\rho^{+}$ ICCM (Figure 3A). These results suggest that mitochondrial calcium uptake and the activation of mtNOS might be an important event in producing bystander factor(s).

It has been reported that ROS scavenger, such as dimethyl sulphoxide, superoxide dismutase, and catalase, can effectively suppress RIBE (Narayanan et al, 1997; Hu et al, 2005). In the present study, $\mathrm{O}_{2}^{\bullet-}$ levels were significantly increased in $\rho^{+} \mathrm{A}_{\mathrm{L}}$ cells after irradiation, but not in $\rho^{0} \mathrm{~A}_{\mathrm{L}}$ cells (Figure $4 \mathrm{~A}$ ), and $\mathrm{RR}$ decreased the $\mathrm{O}_{2}^{\bullet-}$ levels in irradiated $\rho^{+} \mathrm{A}_{\mathrm{L}}$ cells (Figure 4B). The generation of $\mathrm{O}_{2}^{\bullet-}$ might also be related, at least partially, to mitochondria in the irradiated normal cells. Although inhibitors of mitochondrial respiratory chain, such as rotenone, antimycin A, and oligomycin, may cause ROS production, these inhibitors also affect the activity of mtNOS and decrease radiation-induced NO products. Dedkova et al (2004) reported that inhibition of mitochondrial respiratory chain decreased mitochondrial NO production. Using dihydrodichlorofluorescein to determine the ROS/RNS production, Leach et al (2001) observed that rotenone decreased radiation-induced ROS/RNS production. These studies suggested that the activity of the respiratory chain might play an important role in the regulation of mtNOS (Dedkova et al, 2004) and essential components of mitochondrial respiratory chain might be cofactors, which are requires by activation of mtNOS (Bates et al, 1996). Moreover, inhibitors of mitochondrial respiratory chain may collapse the mitochondrial membrane potential, which will decrease the mitochondrial calcium uptake and affect generation of NO by mtNOS. The relationship between radiation-induced ROS and RNS is complex, both of them are important to initiate bystander effects. Inhibitions of mitochondrial respiratory chain increase ROS, but decrease NO, and result in attenuated bystander $\gamma$-H2AX (Figure 1B).

In summary, based on our data and those of others, a working model on how mitochondrial function contributes to RIBE can be postulated. Exposure of cells to ionising irradiation stimulates a reversible mitochondrial permeability transition (Leach et al, 2001), which occurs during activation of permeability pathways in the inner mitochondrial membrane and stimulates mitochondrial $\mathrm{Ca}^{2+}$ uptake (Kanai et al, 2004). The increased $\left[\mathrm{Ca}^{2+}\right]_{\mathrm{m}}$ will activate mtNOS to produce NO. The elevated NO level will inhibit cytochrome oxidase (complex IV) in the respiratory chain and increases $\mathrm{O}_{2}^{\bullet-}$ formation by coenzyme Q (Beltran et al, 2002). The increased ROS will in turn caused a biphasic increase in $\left[\mathrm{Ca}^{2+}\right]_{\mathrm{m}}$ level that will continue to stimulate production of $\mathrm{NO}$ and $\mathrm{O}_{2}^{\bullet-}$, both of which, in part, will react and form peroxynitrite ion $\left(\mathrm{ONOO}^{-}\right)$. The $\mathrm{ONOO}^{-}$can act with protein and DNA that causes continued cellular responses, including later process of bystander. This ring-like generation of $\mathrm{NO}$ in mitochondria by ionising radiation will penetrate cellular membranes as an intercellular signalling molecule, and, finally, results in damages in nonirradiated bystander cells in early process of RIBE.

\section{ACKNOWLEDGEMENTS}

This research was supported by National Nature Science Foundation of China under Grant nos. 10225526 and 30570435, Grant 2006Z026, and Hundred Talents Programme of the Chinese Academy of Sciences, US National Institutes of Health Grants CA 49062 and ES 012888, and Environmental Center Grant ES09089.

Supplementary Information accompanies the paper on British Journal of Cancer website (http://www.nature.com/bjc)

\section{REFERENCES}

Azzam EI, Toledo SM, Little JB (2001) Direct evidence for the participation of gap junction-mediated intercellular communication in the transmission of damage signals from a-particle irradiated to nonirradiated cells. Proc Natl Acad Sci USA 98: 473-478

Balaban RS, Nemoto S, Finkel T (2005) Mitochondria, oxidants, and aging. Cell 120: 483-495
Bates TE, Loesch A, Burnstock G, Clark JB (1995) Immunocytochemical evidence for a mitochondrially located nitric oxide synthase in brain and liver. Biochem Biophys Res Commun 213: 896-900

Bates TE, Loesch A, Burnstock G, Clark JB (1996) Mitochondrial nitric oxide synthase: a ubiquitous regulator of oxidative phosphorylation? Biochem Biophys Res Commun 218: $40-44$ 
Belka C, Rudner J, Wesselborg S, Stepczynska A, Marini P, LeppleWienhues A, Faltin H, Bamberg M, Budach W, Schulze-Osthoff K (2000) Differential role of caspase- 8 and BID activation during radiation- and CD95-induced apoptosis. Oncogene 19(9): 1181-1190

Beltran B, Quintero M, Garcia-Zaragoza E, O'Connor E, Esplugues JV, Moncada S (2002) Inhibition of mitochondrial respiration by endogenous nitric oxide: a critical step in Fas signaling. Proc Natl Acad Sci USA 99(13): $8892-8897$

Burdak-Rothkamm S, Short SC, Folkard M, Rothkamm K, Prise KM (2007) ATR-dependent radiation-induced gamma $\mathrm{H} 2 \mathrm{AX}$ foci in bystander primary human astrocytes and glioma cells. Oncogene 26(7): $993-1002$

Dedkova EN, Ji X, Lipsius SL, Blatter LA (2004) Mitochondrial calcium uptake stimulates nitric oxide production in mitochondria of bovine vascular endothelial cells. J Physiol Cell Physiol 286: C406-C415

Ghafourifar P, Sen CK (2007) Mitochondrial nitric oxide synthase. Front Biosci 12: $1072-1078$

Han W, Wu L, Chen S, Bao L, Zhang L, Jiang E, Zhao Y, Xu A, Hei TK, Yu Z (2007a) Constitutive nitric oxide acting as a possible intercellular signaling molecule in the initiation of radiation-induced DNA double strand breaks in non-irradiated bystander cells. Oncogene 26: 2330-2339

Han W, Wu L, Hu B, Zhang L, Chen S, Bao L, Zhao Y, Xu A, Yu Z (2007b) The early and initiation process of radiation-induced bystander effects involving in the induction of DNA double strand breaks in nonirradiated cultures. $\mathrm{Br} J$ Radiol 80: S7 - S12

Hu B, Han W, Wu L, Feng H, Liu X, Zhang L, Xu A, Hei TK, Yu Z (2005) In $s i t u$ visualization of DSBs to assess the extranuclear/extracellular effects induced by low-dose $\alpha$-particle irradiation. Radiat Res 164: 286-291

Kanai A, Epperly M, Pearce L, Birder L, Zeidel M, Meyers S, Greenberger J, de Groat W, Apodaca G, Peterson J (2004) Differing roles of mitochondrial nitric oxide synthase in cardiomyocytes and urothelial cells. Am J Physiol Heart Circ Physiol 286(1): H13-H21

Kanai AJ, Pearce LL, Clemens PR, Birder LA, VanBibber MM, Choi S, de Groat WC, Peterson J (2001) Identification of a neuronal nitric oxide synthase in isolated cardiac mitochondria using electrochemical detection. Proc Natl Acad Sci USA 98: 14126-14131

Kato K, Giulivi C (2006) Critical overview of mitochondrial nitric-oxide synthase. Front Biosci 11: 2725-2738

Lacza Z, Pankotai E, Csordas A, Gero D, Kiss L, Horvath EM, Kollai M, Busija DW, Szabo C (2006) Mitochondrial NO and reactive nitrogen species production: does mtNOS exist? Nitric Oxide 14(2): 162-168

Leach JK, Black SM, Schmidt-Ullrich RK, Mikkelsen RB (2002) Activation of constitutive nitric-oxide synthase activity is an early signaling event induced by ionizing radiation. J Biol Chem 277(18): 15400-15406

Leach JK, Tuyle GV, Lin PS, Schmidt-Ullrich R, Mikkelsen RB (2001) Ionizing radiation-induced, mitochondria-dependent generation of reactive oxygen/nitrogen. Cancer Res 61(10): 3894-3901
Limoli CL, Giedzinski E, Bonner WM, Cleaver JE (2002) UV-induced replication arrest in the xeroderma pigmentosum variant leads to DNA double-strand breaks, gamma-H2AX formation, and Mre11 relocalization. Proc Natl Acad Sci USA 99: 233-238

Limoli CL, Giedzinski E, Morgan WF, Swarts SG, Jones GDD, Hyun W (2003) Persistent oxidative stress in chromosomally unstable cells. Cancer Res 63: 3107-3111

Liu SX, Davidson MM, Tang X, Walker WF, Athar M, Ivanov V, Hei TK (2005) Mitochondrial damage mediates genotoxicity of arsenic in mammalian cells. Cancer Res 65(8): 3236-3242

Lyng FM, Seymour CB, Mothersill C (2000) Production of a signal by irradiated cells which leads to a response in unirradiated cells characteristic of initiation of apoptosis. $\mathrm{Br} J$ Cancer 83(9): $1223-1230$

Maguire P, Mothersill C, Seymour C, Lyng FM (2005) Medium from irradiated cells induces dose-dependent mitochondrial changes and BCL2 responses in unirradiated human keratinocytes. Radiat Res 163: $384-390$

Morgan WF, Sowa MB (2006) Non-targeted bystander effects induced by ionizing radiation. Mutat Res 616(1-2): 159-164

Mothersill C, Seymour CB (1998) Cell-cell contact during gamma irradiation is not required to induce a bystander effect in normal human keratinocytes: evidence for release during irradiation of a signal controlling survival into the medium. Radiat Res 149: $256-262$

Narayanan PK, Goodwin EH, Lehnert BE (1997) Alpha particles initiate biological production of superoxide anions and hydrogen peroxide in human cells. Cancer Res 57: $3963-3971$

Nazarewicz RR, Zenebe WJ, Parihar A, Larson SK, Alidema E, Choi J, Ghafourifar P (2007) Tamoxifen induces oxidative stress and mitochondrial apoptosis via stimulating mitochondrial nitric oxide synthase. Cancer Res 67(3): $1282-1290$

Shao C, Folkard M, Michael BD, Prise KM (2004) Targeted cytoplasmic irradiation induces bystander responses. Proc Natl Acad Sci USA 101(37) $13495-13500$

Wan XS, Zhou Z, Ware JH, Kennedy AR (2005) Standardization of a fluorometric assay for measuring oxidative stress in irradiated cells. Radiat Res 163: $232-240$

Wu L, Randers-Pehrson G, Xu A, Waldren CA, Geard CR, Yu Z Hei TK (1999) Targeted cytoplasmic irradiation with alpha particles induces mutations in mammalian cells. Proc Natl Acad Sci USA 96: $4959-4964$

Zenebe WJ, Nazarewicz RR, Parihar MS, Ghafourifar P (2007) Hypoxia/ reoxygenation of isolated rat heart mitochondria causes cytochrome release and oxidative stress; evidence for involvement of mitochondrial nitric oxide synthase. J Mol Cell Cardiol 43: 411-419 